\title{
Assessment of nutrient ratios in the leaf of sugarcane grown in Theni district of Tamil Nadu, India
}

\author{
K. Jeevika ${ }^{1 *}$, S. Pragadeesh ${ }^{2}$ and A. Mohamed Haroon ${ }^{3}$ \\ ${ }^{1}$ Department of Soil Science and Agricultural Chemistry, Vanavarayar Institute of Agriculture, Manakkadavu, Pollachi - \\ 642103 (Tamil Nadu), INDIA \\ ${ }^{2}$ Department of Soil science and Agricultural Chemistry, Thanthai Roever Institute of Agriculture and Rural Development, \\ Perambalur - 621212 (Tamil Nadu), INDIA \\ ${ }^{3}$ Department of Soil Science and Agricultural Chemistry, Anbil Dharmalingam Agricultural College and Research \\ Institute, Trichy - 620009 (Tamil Nadu), INDIA \\ *Corresponding author. E-mail: jeevired5@gmail.com
}

Received: April 4, 2015; Revised received: October 8, 2015; Accepted: January 25, 2016

\begin{abstract}
To assess the impact of nutrient ratios N/P, N/K and N/S on sugarcane productivity, a survey was conducted during its grand growth stage (October, November and December) influenced by various yield levels based on soil quality zones in Theni district of Tamil Nadu, India. The leaf samples were collected from cane yielding zones of the district was classified into three categories viz., low yielding (less than $75 \mathrm{t} \mathrm{ha}^{-1}$ ), medium (75 to $\left.100 \mathrm{t} \mathrm{ha}^{-1}\right)$ and high yielding (more than $100 \mathrm{t} \mathrm{ha}^{-1}$ ). Computation of nutrient ratios for sugarcane at its grand growth stage implied that the mean N/P, N/K and N/S ratios $8.31,1.60$ and 15.0 respectively in the third leaf of sugarcane in the high yielding zone resulted in maximum cane yields compared to relatively higher ratios in the top dewlap leaves from soils of low soil quality category which indicates that maintenance of high quality in sugarcane soils influences crop nutrient uptake, optimum nutrient ratios, the yield and quality of sugarcane.
\end{abstract}

Keywords: Grand growth stage, Nutrient ratio, Sugarcane productivity, Theni district

\section{INTRODUCTION}

Plant nutrition revealed nutrient ratios as a better tool for diagnosing the nutrient deficiencies of crops as it takes care of nutrient interrelationships. Further, leaf analysis is widely used as an effective nutrient management technique along with interpretation of soil test results for sustainable sugarcane production McCray and Mylavarapu (2010).

Leaf analysis can be particularly useful in determining the nutrient status of sugarcane because soil samples are taken before sugarcane is planted and not during ratoon crops because of problems in obtaining representative soil samples after banding of fertilizers. Also, leaf analysis can provide information about nitrogen, phosphorus, potassium and sulphur which is not, included in the standard soil tests and it has been used intensively by a limited number of sugarcane growers and has the potential for an expanded role in growers' fertility programs McCray et al. (2010). Therefore, the objective of this study was planned to analyze the nutrient concentration $(\mathrm{N}, \mathrm{P}, \mathrm{K}$ and $\mathrm{S})$ in the Top Visible dewlap leaves (TVD) during grand growth stage (October, November and December) in the varying yield zones of sugarcane and computation of desirable leaf nutrient ratios.

Hence, the present study was undertaken to take up an assessment of leaf nutrient ratios in the low, medium and high cane yielding zones of the district to diagnose the nutrient ratio status in leaves and also aimed in finding out that high yielding zones that resulted in maximum cane yields compared to the top dewlap leaves from soils of low cane yielding zones of the Theni district of Tamil Nadu, India.

\section{MATERIALS AND METHODS}

Study area: Geographically the study area was located in Theni district lying at the foot of western ghats between $9^{\circ} 30^{\prime}$ and $10^{\circ} 12^{\prime}$ North latitude and $77^{\circ} 10^{\prime}$ and $77^{\circ} 42^{\prime}$ 'East longitude at 200-400 meters above sea level in the plains which comprises the major sugarcane growing areas.The sampling area for leaf nutrient ratios analysis was divided into three categories viz.,low yielding ( $<75 \mathrm{t} / \mathrm{ha})$, medium yielding (75- 100 $\mathrm{t} / \mathrm{ha}$ ) and high yielding ( $>100 \mathrm{t} / \mathrm{ha})$ of Theni district during the grand growth stage of the crop. A total of 45 top visible dewlap samples @ 3 samples per block in three replications were collected from all the five blocks covering the low, medium and high yielding zones amounting to 135 numbers of samples (Fig.1). Each sample lot comprised of 10 leaves for reliable representation of nutrient concentration.

Leaf midribs were separated and discarded from leaf 


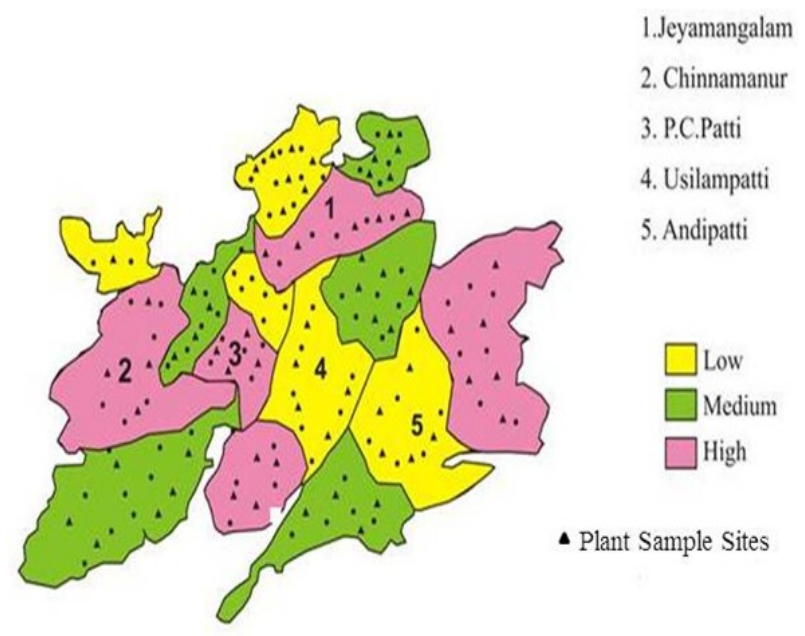

Fig. 1. Sampling sites for leaf nutrient analysis of various cane yielding zones of Theni district of Tamil Nadu.

blades and the blades were washed in deionized water and dried at $60^{\circ} \mathrm{C}$. The dried leaf material was ground to pass through $1 \mathrm{~mm}$ screen in a stainless steel wiley mill. All the ground samples were dried for 12 hours at $65^{\circ} \mathrm{C}$ and digested for analysis of plant nutrient concentrations. The total $\mathrm{N}$ content in the plant sample was determined in Micro Kjeldahl method using di acid extract of $\mathrm{H}_{2} \mathrm{SO}_{4}$ : $\mathrm{HClO}_{4}$ in the ratio of $5: 2$ Humphries (1956). The total Pcontent in the plant sample was determined in triple acid $\left(\mathrm{HNO}_{3}: \mathrm{H}_{2} \mathrm{SO}_{4}\right.$ : $\mathrm{HClO}_{4}$ in the ratio of 9:2:1) digested extract of the plant sample was used by vandomolybdate yellow colour method (Jackson, 1973). The total potassium content in the plant sample was extracted in triple acid mixture and determined by using a flame photometer as prescribed by Toth and Prince (1949). The total sulphur content of the plant sample was analyzed in the diacid extract of $\mathrm{H}_{2} \mathrm{SO}_{4}: \mathrm{HClO}_{4}$ prepared in the ratio of 9:4 by turbidimetric method Jackson (1973).

Statistical analysis: The analytical data on plant nutrient concentrations were processed with statistical parameters viz., mean and Co - efficient of variation (C.V.) by following the methods suggested by Gomez and Gomez (1984).

\section{RESULTS AND DISCUSSION}

Leaf blade nutrient ratios ( $N$ : $P, N$ : $K$ and $N$ : $S$ ) of sugarcane from various soil quality categories: The mean Nitrogen - Phosphorus (N/P) ratio in the low, medium and high yielding zones during the grand growth period of sugarcane was 9.28, 8.77 and 8.31 respectively with a variance of 5.52 percent (Table 1 ).
Where the nutrient ratio (N/P) of cane was high (9.28) in low yielding zones. From the analysis it was found that higher $\mathrm{N}$ and $\mathrm{P}$ uptake resulting in an $\mathrm{N} / \mathrm{P}$ ratio of 8.31 when compared to that of 9.28 in the low yielding zone. Interactions between $\mathrm{N}$ and $\mathrm{P}$ in terms of yields are made in the high yielding zone, included that $\mathrm{N}$ induced increased root growth, enhanced root ability to absorb and translocate $\mathrm{P}$ and increases in $\mathrm{P}$ solubility as a result of decreasing soil $\mathrm{pH}$ which accompanies $\mathrm{NH}_{4}{ }^{+}$absorption.

The mean Nitrogen- Potassium ratios $(\mathrm{N} / \mathrm{K})$ during the grand growth period of sugarcane was $1.60,1.62$ and 1.80 in high, medium and low yielding zones respectively (Table_1). The average N/K ratio in high yielding zone was considerably lower than that of low and medium yielding zones. A high yielding sugarcane crop requires large amounts of these nutrients, and interactions of economic significance often accompany the correction of imbalances of $\mathrm{N}$ and $\mathrm{K}$ in sugarcane production (Miles, 2010). The favorable soil quality parameters of the high yielding zone, assessed in the study was optimum $\mathrm{pH}$, non-saline nature, higher clay content and cation exchange capacity, moderate amounts of organic matter and enhanced availability of $\mathrm{N}, \mathrm{P}, \mathrm{K}, \mathrm{S}$ and micronutrients have contributed to higher uptake of $\mathrm{K}$ through better biophysical environment in the rhizosphere contributing to maximum concentration of nutrients in leaves.

The mean Nitrogen - Sulphur (N/S) ratio in the low, medium and high yielding zones during the grand growth period of sugarcane was 20.88, 14.8 and 15.0 respectively with a variance of 20.4 percent (Table 1).The highest CV (20.4\%) was observed for N/S ratios of the medium yielding zone. In low yielding zone, the nutrient ratio $(\mathrm{N} / \mathrm{S})$ of cane was high (20.88) aided by low organic carbon content of 60 percent in the samples analyzed. Muhammed sarwal et al. (2010) reported the depletion of organic matter under continuous cane cultivation without sufficient addition of organic resources to the soil periodically results in higher N/S ratio in low cane yielding zone.

\section{Conclusion}

A total of 135 samples analyzed for nutrient ratios in the low, medium and high yielding zones during the grand growth period of sugarcane. Interactions between $\mathrm{N}$ and $\mathrm{P}$ in terms of yields in high yielding zones are primarily due to $\mathrm{N}$ induced increases in $\mathrm{P}$ absorption by the plant. This reflects in high yielding zones where the average yield levels were maximum to $140 \mathrm{t} \mathrm{ha}^{-1}$ compared to the medium and low yielding

Table 1. Computation average of N/P, N/K and N/S ratios in the variable cane yielding zones of Theni district of Tamil Nadu.

\begin{tabular}{lllll}
\hline \multirow{2}{*}{ Nutrient ratios } & \multicolumn{3}{c}{ Cane yielding zones } & \multirow{2}{*}{ Coefficient of variation (\%) } \\
\cline { 2 - 4 } & Low & Medium & High & 5.52 \\
N/P & 9.28 & 8.77 & 8.31 & 6.58 \\
N/K & 1.80 & 1.62 & 1.60 & $\mathbf{2 0 . 4}$ \\
N/S & 20.88 & 14.8 & 15.0 & \\
\hline
\end{tabular}


zones. A high yielding sugarcane crop requires large amounts $\mathrm{N}$ and $\mathrm{K}$ for cane production. In the low cane yielding zone, the crops were with deficient $\mathrm{N}$ concentrations and accordingly the leaf S concentrations were below the critical level indicating the necessity for adequate supply of available $\mathrm{N}$ for enhancing the uptake of sulphur by the sugarcane crop. Therefore, compared to low yielding zones the maintenance of high quality in sugarcane soils might influence crop nutrient uptake with optimum nutrient ratios and results in improved quality and high yield of sugarcane.

\section{REFERENCES}

Gomez, K.A. and Gomez, A.A. (1984). Statistical procedures for Agricultural Research, 2nd end. John Wiley Sons, New York. pp. 680.

Humphries, E.S. (1956). Mineral components and ash analysis. Modern methods of plant analysis, Springer verlag. Berlin, pp. 468-472.

Jackson, M.L. (1973). Soil Chemical analysis, Prentice Hall of India (Pvt.) Ltd., New Delhi.
McCray, J.M. and Mylavarapu, R. (2010). Sugarcane nutrient management using leaf analysis. Florida Cooperative Extension Service Pub. SS-AGR-335.

McCray, J.M., Rice, R.W., Lang, T.A. and Les Baucum. (2010). Sugarcane plant nutrient diagnosis. Florida Cooperative Extension Service Fact Sheet SS-AGR128. UF/IFAS Electronic Data Information Source (EDIS) Database (http://edis.ifas.ufl.edu/sc075). University of Florida, Gainesville.

Miles, N. (2010). Challenges and opportunities in leaf Nutrient data interpretation. Proceedings of the South African Sugar Technologists Association83: 205 - 215.

Muhammad Aleem Sarwar, Muhammed Ibrahim Muhammad Tahir, Kafeelahamad, ZafarIqbal khan and EhsanElahiValeem. (2010). Appraisal of pressmud and inorganic fertilizers on soil properties, yield and sugarcane quality. Pakistan Journal of Botany 42 (2): 1361 - 1367, 2010.

Toth, S.J. and Prince, A. (1949). Estimation of cation exchange capacity and exchangeable calcium, potassium and sodium contents of soils by flame photometer techniques. Soil Science, 67: 439-445. 